Mice lacking interleukin-18 gene display behavioral changes in animal models of psychiatric disorders : Possible involvement of immunological mechanisms

\author{
Lisboa, S. F.
}

2018-01-15

Lisboa, S F , Issy, A C , Biojone , C, Montezuma, K, Fattori , V , Del-Bel, E A, Guimaraes , F S , Cunha , F Q , Verri , W A \& Joca, S R L 2018 , ' Mice lacking interleukin-18 gene display behavioral changes in animal models of psychiatric disorders : Possible involvement of immunological mechanisms ' , Journal of Neuroimmunology, vol. 314 , pp. 58-66 . https://doi.org/10.1016/j.jneuroim.2017.11.008

http://hdl.handle.net/10138/299472

https://doi.org/10.1016/j.jneuroim.2017.11.008

publishedVersion

Downloaded from Helda, University of Helsinki institutional repository.

This is an electronic reprint of the original article.

This reprint may differ from the original in pagination and typographic detail.

Please cite the original version. 


\title{
Mice lacking interleukin-18 gene display behavioral changes in animal models of psychiatric disorders: Possible involvement of immunological mechanisms
}

\author{
S.F. Lisboa ${ }^{\mathrm{a}, \mathrm{b}, *}$, A.C. Issy ${ }^{\mathrm{b}, \mathrm{c}}$, C. Biojone ${ }^{\mathrm{d}}$, K. Montezuma ${ }^{\mathrm{a}, \mathrm{b}}$, V. Fattori ${ }^{\mathrm{e}}$, E.A. Del-Bel ${ }^{\mathrm{b}, \mathrm{c}}$, \\ F.S. Guimarães ${ }^{\mathrm{a}, \mathrm{b}}$, F.Q. Cunha ${ }^{\mathrm{a}}$, W.A. Verrie ${ }^{\mathrm{e}}$, S.R.L. Joca ${ }^{\mathrm{b}, \mathrm{f}, \mathrm{g}, * * *}$ \\ a Department of Pharmacology, Medical School of Ribeirão Preto, University of São Paulo (FMRP/USP), Brazil \\ ${ }^{\mathrm{b}}$ Center for Interdisciplinary Research on Applied Neurosciences (NAPNA), University of São Paulo, Brazil \\ ${ }^{\mathrm{c}}$ Dental School of Ribeirão Preto, University of São Paulo (FOR/USP), Brazil \\ ${ }^{\mathrm{d}}$ Neuroscience Center, University of Helsinki, Finland \\ e Department of General Pathology, Biological Sciences Center, Londrina State University (CCB/UEL), Brazil \\ ${ }^{\mathrm{f}}$ Department of Physics and Chemistry, School of Pharmaceutical Sciences of Ribeirão Preto (FCFRP/USP), University of São Paulo, Brazil \\ ${ }^{g}$ Translational Neuropsychiatry Unit, Department of Clinical Medicine, Aarhus University, Denmark
}

\begin{abstract}
A B S T R A C T
Preclinical and clinical evidence suggests pro-inflammatory cytokines might play an important role in the neurobiology of schizophrenia and stress-related psychiatric disorders. Interleukin-18 (IL-18) is a member of the IL-1 family of cytokines and it is widely expressed in brain regions involved in emotional regulation. Since IL-18 involvement in the neurobiology of mental illnesses, including schizophrenia, remains unknown, this work aimed at investigating the behavior of IL-18 null mice (KO) in different preclinical models: 1 . the prepulse inhibition test (PPI), which provides an operational measure of sensorimotor gating and schizophrenic-like phenotypes; 2. amphetamine-induced hyperlocomotion, a model predictive of antipsychotic activity; 3 . residentintruder test, a model predictive of aggressive behavior. Furthermore, the animals were submitted to models used to assess depressive- and anxiety-like behavior. IL-18KO mice showed impaired baseline PPI response, which was attenuated by D-amphetamine at a dose that did not modify PPI response in wild-type (WT) mice, suggesting a hypodopaminergic prefrontal cortex function in those mice. D-Amphetamine, however, induced hyperlocomotion in IL-18KO mice compared to their WT counterparts, suggesting hyperdopaminergic activity in the midbrain. Moreover, IL-18KO mice presented increased basal levels of IL-1 $\beta$ levels in the hippocampus and TNF- $\alpha$ in the prefrontal cortex, suggesting an overcompensation of IL-18 absence by increased levels of other proinflammatory cytokines. Although no alteration was observed in the forced swimming or in the elevated plus maze tests in naïve IL-18KO mice, these mice presented anxiogenic-like behavior after exposure to repeated forced swimming stress. In conclusion, deletion of the IL-18 gene resembled features similar to symptoms observed in schizophrenia (positive and cognitive symptoms, aggressive behavior), in addition to increased susceptibility to stress. The IL-18KO model, therefore, could provide new insights into how changes in brain immunological homeostasis induce behavioral changes related to psychiatric disorders, such as schizophrenia.
\end{abstract}

\section{Introduction}

Over the last two decades, several studies have suggested an important bidirectional interaction between psychological stress and the immune system (Glaser and Kiecolt-Glaser, 2005; Kusnecov and Rabin, 1994; Segerstrom and Miller, 2004). In fact, pro-inflammatory cytokines, such as interleukin 1 (IL-1), IL-6, IL-18 and tumor necrosis factor alpha (TNF- $\alpha$ ) are constitutively expressed in different limbic brain regions of the rodent brain (Goshen and Yirmiya, 2009; Pickering et al., 2005; Stellwagen and Malenka, 2006; Tonelli and Postolache, 2005) and the administration of pro-inflammatory cytokines produces a core of endocrine, neurochemical, and behavioral changes that are

* Correspondence to: SF Lisboa, Pharmacology Department, Medical School of Ribeirão Preto, University of São Paulo (FMRP-USP), Av Café 3900, Monte Alegre, Ribeirão Preto-SP 14049-900, Brazil.

** Correspondence to: SRL Joca, Department of Physics and Chemistry, Laboratory of Pharmacology, FCFRP-USP, Av Café, s/n, Monte Alegre, Ribeirão Preto-SP 14040-903, Brazil.

E-mail addresses: sabrinalisboa@usp.br, sa_lisboa@hotmail.com (S.F. Lisboa), samia@usp.br (S.R.L. Joca). 
similar to those produced by stress exposure (Goshen and Yirmiya, 2009; Kwon et al., 2008; Madrigal et al., 2002; O'Connor et al., 2003). On the other hand, inhibiting the activity of pro-inflammatory cytokines in animals often attenuates stress-induced consequences (Goshen et al., 2007), thus suggesting pro-inflammatory cytokines play a prominent role in the modulation of neuroendocrine, behavioral and emotional responses to stress (Goshen and Yirmiya, 2009).

Altered levels of pro-inflammatory cytokines (TNF- $\alpha$, IL-1 $\beta$ and IL6) are also found in the serum and in the brain of psychiatric patients (Anisman and Merali, 2002; Levine et al., 1999; Licinio and Wong, 1999; Maes, 1995, 1999; Penninx et al., 2003; Tuglu et al., 2003) and chronic treatment with psychotropic medication, specially antidepressants and antipsychotics, can correct such imbalances. Moreover, the use of interferon $\alpha$ (IFN- $\alpha$ ) produce significant changes in brain metabolism as well as psychotic and depressive symptoms in humans (Capuron et al., 2007; Drozdz et al., 2007). Altogether, these studies highlight the possibility that cytokines could contribute to the development of stress-related mental illnesses, such as anxiety, depression, and schizophrenia (Papanicolaou et al., 1998; Schiepers et al., 2005; Yirmiya, 2000).

Interleukine-18 (IL-18) is a pleiotropic cytokine (Nakanishi et al., 2001) member of the IL- 1 family. IL-18 shares with IL-1 $\beta$ the same converting enzyme (caspase 1 ) that cleaves its precursor pro-IL-18 to yield the active IL-18 (Okamura et al., 1995). This cytokine and its receptors are constitutively expressed in astrocytes, microglia, neurons and ependymal cells of different brain areas of the rodent brain, including limbic regions (Alboni et al., 2009; Culhane et al., 1998; Felderhoff-Mueser et al., 2005; Wheeler et al., 2000). Moreover, IL-18 can regulate neurotransmitter release (Kanno et al., 2004), modulate neuronal excitability (Kanno et al., 2004), stress-induced microglial activation (Sugama et al., 2007), and interfere with plastic events in the CNS (Curran and O'Connor, 2001). Despite that, IL-18 involvement in the neurobiology of psychiatric disorders remains poorly investigated.

Schizophrenic patients have increased levels of IL-18 in the serum (Monji et al., 2009; Tanaka et al., 2000; Zhang et al., 2013) and polymorphisms in IL-18 gene have been related to specific clinical manifestations of schizophrenia, such as perception disorder and aggression, but were not directly connected with the risk of disease (Liu et al., 2011). Higher plasma levels of IL-18 are observed in first-episode psychosis and are positively correlated with cognitive impairments in chronic schizophrenic patients (Orhan et al., 2017, Wu et al., 2016). Moreover, IL-18 increase in the chronic phase of schizophrenia is positively correlated with positive and negative symptoms (Xiu et al., 2012). Although these recent evidences suggest IL-18 may play an important role in schizophrenia neurobiology, it is not known how IL18 absence would affect behaviors predictive of schizophrenic-like phenotype. Additionally, there is scarce information about IL-18 involvement in the neurobiology of other mental disorders, such as anxiety and depression (Eisener-Dorman et al., 2010; Too et al., 2014; Yaguchi et al., 2010; Yamamoto et al., 2010),

Based on the aforementioned evidence, the present study aimed at investigating the behavioral effects induced by IL-18 absence in mice submitted to preclinical models used to study schizophrenia and stressrelated psychiatric disorders, including: prepulse inhibition (PPI) test; amphetamine-induced hyperlocomotion; social isolation induced aggression; elevated plus-maze and forced swimming test. Considering that prepulse inhibition (PPI) disruption possibly reflects the difficulty of suppressing or filtering excessive information in schizophrenic patients (Braff et al., 2001; Swerdlow et al., 2008), PPI deficits across species, has been considered to reflect a schizophrenic-like phenotype (Swerdlow et al., 2008) and evaluation of this behavior in rodents is relevant to schizophrenia studies. Moreover, since psychotic patients release more dopamine after stimulation with amphetamine than normal individuals, possibly due to increased midbrain dopaminergic activity (Abi-Dargham et al., 2009), the hyperlocomotion-induced by amphetamine can be used to investigated increased activity in this brain region. Aggression and antisocial behavior are aften observed in schizophrenia and it can be induced by social isolation (Buckley et al., 2011; Buckley et al., 2004; Serper, 2011; Soyka, 2011). Therefore, we also investigated if social-isolation induced aggressive behavior would be altered in IL-18 KO mice. Last, considering the well-known involvement of proinflammatory cytokines in responses evoked by stress exposure, we also evaluated if IL-18 KO present different behaviors in the elevated plus maze and forced swimming stress, in addition to increased susceptibility to stress exposure. Finally, we also measured IL$1 \beta, \mathrm{IL}-33$, and TNF- $\alpha$ in the medial prefrontal cortex (MPFC), striatum (ST) and hippocampus (HIP), brain regions that have been associated with those disorders.

\section{Material and methods}

\subsection{Animals}

210 mice were used in this study. This study was conducted in male recessive homozygous IL-18 deficient (KO) (Balb/c background) and Balb/c wild-type control mice (9-12 weeks). The IL-18KO mice, a donation from Dr. Foo Liew (University of Glasgow), were generated as previously described in C57 BL/6 mice and backcrossed to Balb/c for eight generations (Wei et al., 1999). They were provided by our local Animal farm facility, and their genetic status was confirmed by PCR (Wei et al., 1999). After arriving at the Animal Care Unit of the Department of Pharmacology, Medical School of Ribeirao Preto, University of Sao Paulo, animals were housed in groups of 8-10 animals per cage, in a temperature-controlled room $\left(24 \pm 1{ }^{\circ} \mathrm{C}\right)$ under standard laboratory conditions ( $12 \mathrm{~h}$ light/ $12 \mathrm{~h}$ dark, lights on at $06: 30 \mathrm{~h}$ ) with free access to food and water. Procedures were conducted in conformity with the Brazilian Society of Neuroscience and Behavior guidelines for the care and use of laboratory animals, which comply with international laws. All tests were conducted in the light phase.

\subsection{Drugs}

Powdered D-amphetamine (D-Amph; Sigma) was dissolved in saline $(0.9 \%)$. The solutions were prepared immediately before use and injected via intraperitoneal (i.p.) in a volume of $10 \mathrm{ml} / \mathrm{kg}$.

\subsection{Experimental procedure}

Each behavioral test was performed with independent groups of animals. WT and KO mice were randomly assigned to the different experimental groups.

\subsection{Behavioral response of IL-18KO mice in Prepulse Inhibition (PPI) Test and Amphetamine effects}

Mice were submitted to the PPI test as described below to record baseline responses. One week later, animals were resubmitted to the PPI test after pharmacological challenge with vehicle $(10 \mathrm{ml} / \mathrm{kg})$ or amphetamine $(5 \mathrm{mg} / \mathrm{kg} / \mathrm{i} . \mathrm{p}$.), injected $30 \mathrm{~min}$ before test.

PPI of the acoustic startle reflex refers to the reduction in the startle response magnitude to a startling acoustic 'pulse' stimulus when it is shortly preceded by a weaker non-startling 'prepulse' stimulus (Hoffman and Ison, 1980). Startle response amplitude recording and PPI were conducted simultaneously in two identical startle systems (Med Associates, Inc., USA), as previously described (Issy et al., 2009). The cages were calibrated before the test (adjusted to 150 units) to ensure equal sensitivity of both response platforms during the test period. Pulse (pulse alone) was a burst of white noise of $105 \mathrm{~dB}$ with a rise/decay of $5 \mathrm{~ms}$ and duration of $20 \mathrm{~ms}$. Prepulse was a pure tone of 80,85 or $90 \mathrm{~dB}$ intensity with frequency of $7 \mathrm{kHz}$ and $10 \mathrm{~ms}$ of duration. The interval between the onset of the prepulse and the pulse was $100 \mathrm{~ms}$ and the inter-stimuli interval was of $30 \mathrm{~s}$. Prepulse alone did not 
induce startle responses. PPI test consisted of 64 trials pseudo randomly divided into eight different categories: pulse alone, prepulse plus pulse, prepulse alone and null, where no stimulus was presented. Each trial type was presented at least eight times. The level of PPI was determined by expressing the prepulse + pulse $(\mathrm{PP}+\mathrm{P})$ startle amplitude as a percentage of pulse-alone (P) startle amplitude [\% PPI $=100-(100 \times \mathrm{PP}+\mathrm{P} / \mathrm{P})]$. Using this formula, a $0 \%$ value denotes no difference between startle reflex response to the pulse alone and to the prepulse + pulse and, consequently, no PPI.

\subsection{Amphetamine-induced hyperlocomotion}

This test was performed in an open field (OF), as previously described (Leite et al., 2008). Twenty minutes before the exposure to the $\mathrm{OF}$, animals received an intraperitoneal injection of vehicle or D-Amphetamine $(0.625,1.25,2.5,5$ or $7.5 \mathrm{mg} / \mathrm{kg})$. The exploratory activity (distance moved and maximum speed) was videotaped for $5 \mathrm{~min}$ and Any-Maze software (V. 4.5, Stoelting, IL, USA) was employed for behavioral analysis. It detects the position of the animal in the open field and calculates the distance moved and maximum speed.

\subsection{Resident-intruder test}

The experiments were carried out as previously described, with some modifications (Lisboa et al., 2007). IL-18KO mice and WT were isolated during 4 weeks in polycarbonate cages $(30 \times 20 \times 13 \mathrm{~cm}$; Beiramar). After that period, a non-isolated intruder mouse, from the same lineage and similar age, was introduced in the resident home cage for $10 \mathrm{~min}$. Behavior was videotaped and the latency to the first attack (bite) by the resident, the total time of attacks and the number of attacks were evaluated.

\subsection{Exploratory activity}

Briefly, the animals were placed in a circular open field (OF) arena ( $40 \mathrm{~cm}$ in diameter with a $50 \mathrm{~cm}$ high Plexiglas wall) for $6 \mathrm{~min}$, as previously described (Zanelati et al., 2009). The exploratory activity was videotaped and Any-Maze software (V. 4.5, Stoelting, IL, USA) was employed for behavioral analysis. It detects the position of the animal in the open field and calculates the distance moved.

\subsection{Forced swimming test}

Forced Swimming Test (FST) was performed according to the method first described by Porsolt and colleagues (Porsolt et al., 1977), with minor modifications, to access antidepressant-like effects in mice. Animals were submitted, individually, to the forced swimming in glass cylinders (height $25 \mathrm{~cm}$, diameter $17 \mathrm{~cm}$ ) containing $10 \mathrm{~cm}$ of water for 6 min, during 5 consecutive days. The total duration of immobility (characterized by slow movements only to avoid drowning) was videotaped and measured during the last 4-min period by a trained observer that was blind to the mouse condition on the first, third and fifth day (Kumar et al., 2010). The water was changed after each trial to maintain the temperature at $23-25{ }^{\circ} \mathrm{C}$ and to prevent the influence of alarm substances (Abel and Bilitzke, 1990).

\subsection{Elevated plus-maze test}

The elevated plus-maze (EPM) apparatus consisted of two opposite wood open arms $(34 \times 6.5 \mathrm{~cm})$, crossed at right angle by two arms of the same dimensions enclosed by $15-\mathrm{cm}$ high walls with no roof. The maze was located $50 \mathrm{~cm}$ above the floor. The animals were placed individually in the center of the maze for free exploration during $5 \mathrm{~min}$. The behavior was videotaped and the percentages of entries and time spent in the open arms $[100 \times$ open $/($ open + enclosed) $]$ during the $5 \mathrm{~min}$ of test were evaluated by the Any-Maze software (V. 4.5,
Stoelting, IL, USA). Exposure to the EPM was performed in naïve WT and $\mathrm{KO}$ mice or on the first day after 5 days of repeated submission to the FST and the data were represented as stated above.

\subsection{Cytokines measure by ELISA sandwich}

Cytokines measure was performed in the brain areas collected from WT and KO mice that did not undergo any experimental intervention (naïve). Levels of IL-1 $\beta$, IL-33 and TNF- $\alpha$ were measured in the medial prefrontal cortex (MPFC), striatum (ST) and hippocampus (HIP) and given at $\mathrm{pg} / \mu \mathrm{g}$ of total protein. IL-18KO and WT animals were anesthetized with $5 \%$ chloral hydrate (Sigma; $10 \mathrm{ml} / \mathrm{kg}$ ), decapitated and had their brains removed. The structures were dissected and immediately immersed in lyses buffer solution $(137 \mathrm{mM} \mathrm{NaCl}, 20 \mathrm{mM}$ Tris-HCl, $\mathrm{pH} 8.0,10 \%(\mathrm{v} / \mathrm{v})$ glycerol) containing protease inhibitor cocktail (10\% v/v; Sigma). The tissues were homogenized in this buffer and centrifuged (10 min, 10,000 rpm, $4^{\circ} \mathrm{C}$ ).

The supernatants were collected and storage at $-70^{\circ} \mathrm{C}$ until use. Briefly, 96 wells plates were incubated with primary antibodies against IL-1 $\beta$, TNF- $\alpha$ or IL-33 overnight (kits Duo Set, R\&D System). Then the plates were washed and incubated with BSA $1 \%$, washed again and the samples or standard curve were added and incubated for $24 \mathrm{~h}$ at $4{ }^{\circ} \mathrm{C}$. After that, the plates were washed and the secondary antibodies were added and incubated for $1 \mathrm{~h}$ at room temperature. Avidine-HRP (1:5000) was added for $30 \mathrm{~min}$. The plates were washed, color reagent OPD was added and the plates were kept in the dark in room temperature for $20 \mathrm{~min}$. The enzymatic reaction was stopped with $\mathrm{H}_{2} \mathrm{SO}_{4}$ ( $1 \mathrm{M}, 50 \mu \mathrm{l} /$ well) and the absorbance was determined at $490 \mathrm{~nm}$. The data were obtained comparing samples values of absorbance with the standard curve absorbance (Cunha et al., 2000).

\subsection{Statistical analysis}

Data were analyzed by IBM ${ }^{\circledR}$ SPSS $^{\circledR}$ Statistics software (version 21). Unpaired $t$-tests were employed to analyze the aggressive behavior and data from OF, FST and EPM. Cytokine data did not achieve homogeneity of variances and were analyzed by non-parametric analysis (Mann-Whitney). One-way analysis of variance (ANOVA) was employed for analysis of the acoustic startle response to pulse alone. The percentage of PPI was analyzed by repeated measures ANOVA with prepulse intensity as the repeated measure and the genotype and treatment as the between-subject factors. Hyperlocomotion induced by D-Amph was analyzed by two-way ANOVA with the genotype (KO or WT) and doses of drug as independent factors. In case of significant interaction between the factors, one-way ANOVA was performed to compare the different groups, followed by Duncan post hoc test. The behavioral data were expressed as mean \pm SEM. Difference was considered significant at $\mathrm{p} \leq 0.05$.

\section{Results}

\subsection{Behavior of IL-18KO and WT mice in PPI test and effect of amphetamine}

The statistical analysis showed a significant effect of prepulse intensity $\left(\mathrm{F}_{2,23}=17.67, \mathrm{p}<0.0001\right)$, interaction between prepulse intensity, genotype and treatment and a tendency to a treatment effect $\left(\mathrm{F}_{1,24}=3.2, \mathrm{p}=0.08\right)$. The baseline (pre-treatment) PPI at prepulse intensity of $90 \mathrm{~dB}$ of IL-18KO mice was lower, which was improved after D-Amph treatment ( $\mathrm{p}<0.05$, Duncan). At prepulse intensity of $80 \mathrm{~dB}$, although KO mice did not present lower PPI at baseline, the response was higher after D-Amph ( $\mathrm{p}<0.05$, Duncan; $\mathrm{n}=6-8$ animals/group; Fig. 1A). 


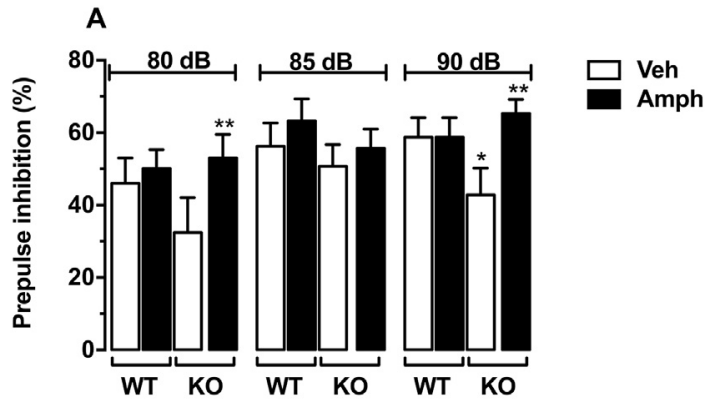

B
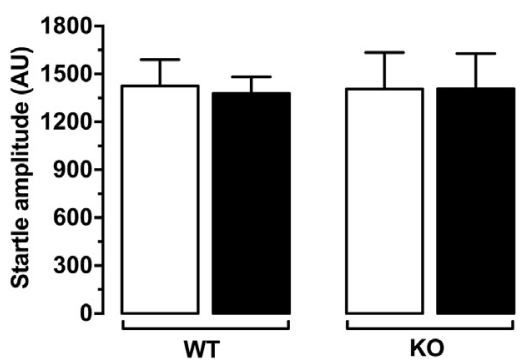

Fig. 1. A) IL-18 null mice (IL-18KO) performance in the prepulse inhibition (PPI) test and effect of D-Amphetamine (D-Amph). IL-18KO mice expressed PPI deficit when compared to their wild type counterparts (WT) at higher prepulse intensity tested ( $90 \mathrm{~dB}$ ). Pretreatment with D-Amph prevented disruption of PPI at $90 \mathrm{~dB}$ and increased PPI at $80 \mathrm{~dB}$. All data are expressed as mean \pm SEM. * $\mathrm{p}<0.05$ different from WT and ${ }^{* *} \mathrm{p}<0.05$ different from KO. Repeated measures, two-way ANOVA and Duncan posthoc test. B) Performance of IL-18KO mice in the startle response amplitude in arbitrary units (AU). There was no difference between WT and KO mice in startle response at baseline or after D-Amph treatment. Data are expressed as mean \pm SEM.

\subsection{Behavior of IL-18KO and WT mice in the startle response and effect of amphetamine}

There was no difference between baseline startle responses (pulsealone, arbitrary units) or startle responses after treatment with amphetamine in WT and KO mice ( $\mathrm{p}>0.05 ; \mathrm{n}=6-8$ animals/group; Fig. 1B).

\subsection{Amphetamine induced hyperlocomotion in $I L-18 K O$ and WT mice}

In the distance moved (Fig. 2A; $\mathrm{n}=5-10$ animals/group), there was a significant effect of genotype $\left(\mathrm{F}_{1,68}=9.5, \mathrm{p}<0.05\right)$, treatment $\left(\mathrm{F}_{4,68}=31.6, \quad \mathrm{p}<0.0001\right)$ and interaction between factors $\left(\mathrm{F}_{4,68}=6.8, \mathrm{p}<0.0001\right)$. In the maximum speed (Fig. $2 \mathrm{~B}$ ), there was only significant effect of treatment $\left(\mathrm{F}_{4,68}=6.4, \mathrm{p}<0.0001\right)$.

D-Amph 5.0 and $7.5 \mathrm{mg} / \mathrm{kg}$ significantly increased the distance moved in WT and KO mice $\left(\mathrm{F}_{9,68}=16.7\right.$, ANOVA $\mathrm{p}<0.0001$, Duncan, $\mathrm{p}<0.05$ ). Although $7.5 \mathrm{mg} / \mathrm{kg}$ induced a greater response than $5.0 \mathrm{mg} / \mathrm{kg}$ in WT mice (Duncan, $\mathrm{p}<0.05$ ), this latter dose promoted a higher response in the KO mice. Both D-Amph 5 and $7.5 \mathrm{mg} / \mathrm{kg}$ increased maximum speed in $\mathrm{KO}$ mice, whereas only $7.5 \mathrm{mg} / \mathrm{kg}$ increased this parameter in WT mice $\left(\mathrm{F}_{9,68}=3.3\right.$, ANOVA between subjects $\mathrm{p}<0.005$, Duncan, $\mathrm{p}<0.05$ ).

\subsection{Evaluation of aggressive and impulsive behavior in the resident-intruder} test

IL-18KO ( $\mathrm{n}=7-9$ animals/group) mice presented increased impulsive and aggressive-behavior expressed by lower latency to the first bite $\left(\mathrm{t}_{14}=2.6, \mathrm{p}<0.05\right.$; Fig. $\left.3 \mathrm{~A}\right)$ and increased total attack time (log transformation; $\mathrm{t}_{13}=2.3, \mathrm{p}<0.05$; Fig. $3 \mathrm{C}$ ), respectively. There was also a tendency to increase the number of attacks (log transformation; $\mathrm{t}_{13}=1.4, \mathrm{p}=0.1$; Fig. 3B).
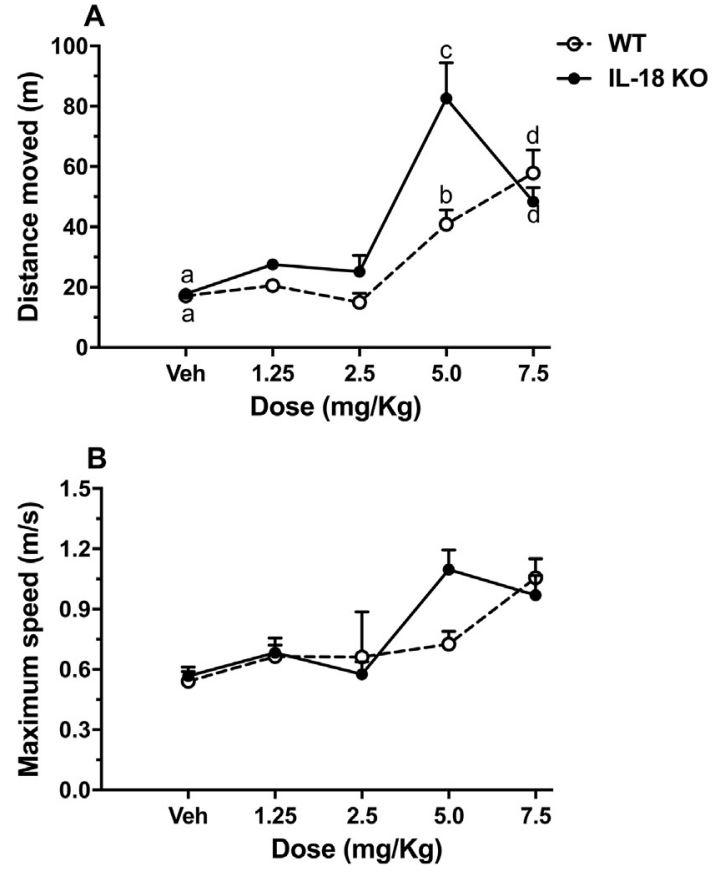

Fig. 2. Effect induced by D-Amph in IL-18KO mice submitted to an open-field. D-Amph induced hyperlocomotion both in WT and KO mice, represented by increased distance (A) and maximum speed (B). D-Amph at $5 \mathrm{mg} / \mathrm{kg}$ induced the highest effect in KO mice. Data are expressed as mean \pm SEM. Means represented by different letters are significantly different from each other. Two-way ANOVA and Duncan post-hoc test; $n=9-10$ /group.

\subsection{Behavioral phenotype in the locomotor activity, elevated plus maze (EPM) and forced swimming (FST) tests}

IL-18 KO animals presented a significant reduction in the total distance moved in the open field test ( $=9 /$ group; IL-18 KO: $\mathrm{t}_{16}=4.796, \mathrm{p}<0.0005$; Fig. 4A). IL-18 naïve KO mice neither present any significant difference in behavior evaluated in the EPM compared to naïve WT mice (percentage of entries in the open arms - WT: $9.5 \pm 2.4$, KO: $11.9 \pm 2.6, t=0.7$, d.f. $=20, \mathrm{p}>0.05$; percentage of time in the open arms - WT: $5.1 \pm 1.1$, KO:4.3 $\pm 1.1, t=0.5$, d.f. $=12, p>0.05$; number of entries in the enclosed arms: $t=1.267$, d.f. $=12, \mathrm{p}>0.05 ; \mathrm{n}=10-12 /$ group; Fig. 4B) nor in the FST test (WT: $167.9 \pm 6.3, \mathrm{KO}=168.2 \pm 9.0, t=0.03$, d.f. $=25$, $\mathrm{p}>0.05 ; \mathrm{n}=13-14$ /group; Fig. 4C).

\subsection{Evaluation of behavioral changes in the EPM induced by repeated} forced swim stress

IL-18KO mice did not present significant differences in the immobility time across the repeated forced swimming sessions $(t=1.4$, d.f. $=20, \mathrm{p}>0.05 ; \mathrm{n}=10-12 /$ group; Fig. 5A). However, when evaluated one day after the last swimming session, KO mice presented an anxiogenic-like behavior, represented by decreased percentage of entries into the open arms $(t=2.8$, d.f. $=20, \mathrm{p}<0.05 ; \mathrm{n}=10-12$ / group). There was also a tendency to a decreased percentage of time spent in these arms $(t=2.0$, d.f. $=20, \mathrm{p}=0.06$ ) (Fig. $5 \mathrm{~B}$ ). No effect was observed in the number of enclosed arms (WT: $14.7 \pm 1.5$, KO:19.1 $\pm 2.7, \mathrm{n}=11-12$ /group; $\mathrm{p}>0.05$; data not shown).

\subsection{Brain levels of cytokines in IL-18KO and WT mice}

In the hippocampus, KO mice $(\mathrm{n}=7)$ presented increased levels of IL-1 $\beta(t=2.6$, d.f. $=13, \mathrm{p}<0.05)$, but not of TNF- $\alpha(\mathrm{p}>0.05)$ or IL-33 ( $>0.05)$, compared to WT mice $(n=9)$. In the prefrontal cortex, KO mice $(\mathrm{n}=6)$ presented increased levels of TNF- $\alpha(t=2.5$, d.f. $=12, p<0.05)$ and a tendency for increased IL- $1 \beta(\mathrm{p}=0.1)$, but 

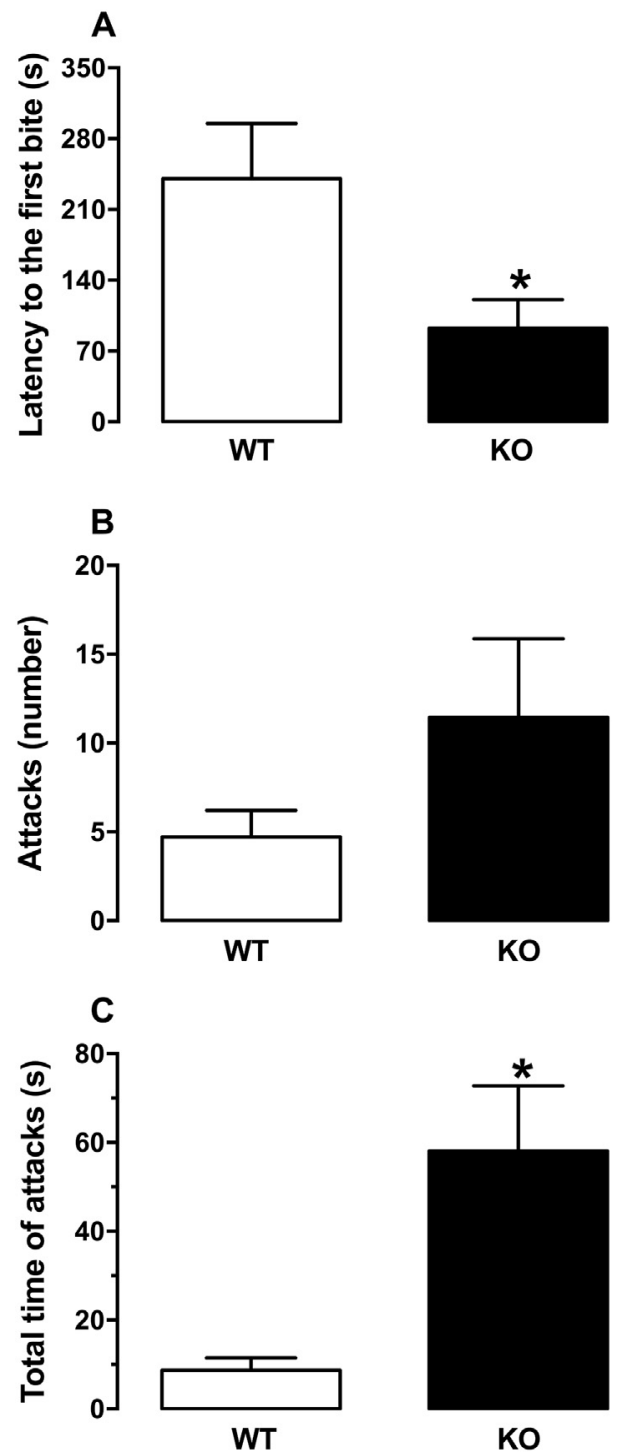

Fig. 3. Evaluation of aggressive behavior in IL-18KO mice. IL-18KO mice presented higher aggressive-like behavior represented by A) lower latency to the first bite, B) a tendency to increased number of attacks and C) increased total time of attacks and compared to WT mice. Data are expressed as mean \pm SEM. *p $<0.05$ compared to WT mice, Student $t$-test; $\mathrm{n}=7-9 /$ group.

no alteration in IL-33 level ( $\mathrm{p}>0.05)$ compared do WT mice $(\mathrm{n}=8)$. In the striatum, there was a trend to increased IL- $1 \beta$ levels $(\mathrm{p}=0.1)$ in the KO mice $(n=7)$ compared to WT mice $(n=6)$ (Table 1$)$.

\section{Discussion}

Our results suggest that IL-18KO mice present behavioral changes that resemble some features of schizophrenic patients. Despite a discrete impairment of baseline PPI, these animals showed differential response to amphetamine challenge either in the PPI test or in the locomotor evaluation. In addition, these animals presented increased aggression, greater sensitivity to repeated stress exposure, and enhanced levels of cytokines in limbic regions, such as hippocampus and prefrontal cortex. On the other hand, IL-18KO mice did not show significant behavioral changes when tested in paradigms that are predictive of anxiety- or depressive-like behaviors.

Polymorphisms in IL-18 gene have been related to specific clinical manifestations of schizophrenia, such as perception disorder and aggression, but were not directly connected with the risk of disease (Liu et al., 2011). Altered blood levels of IL-18 have been consistently
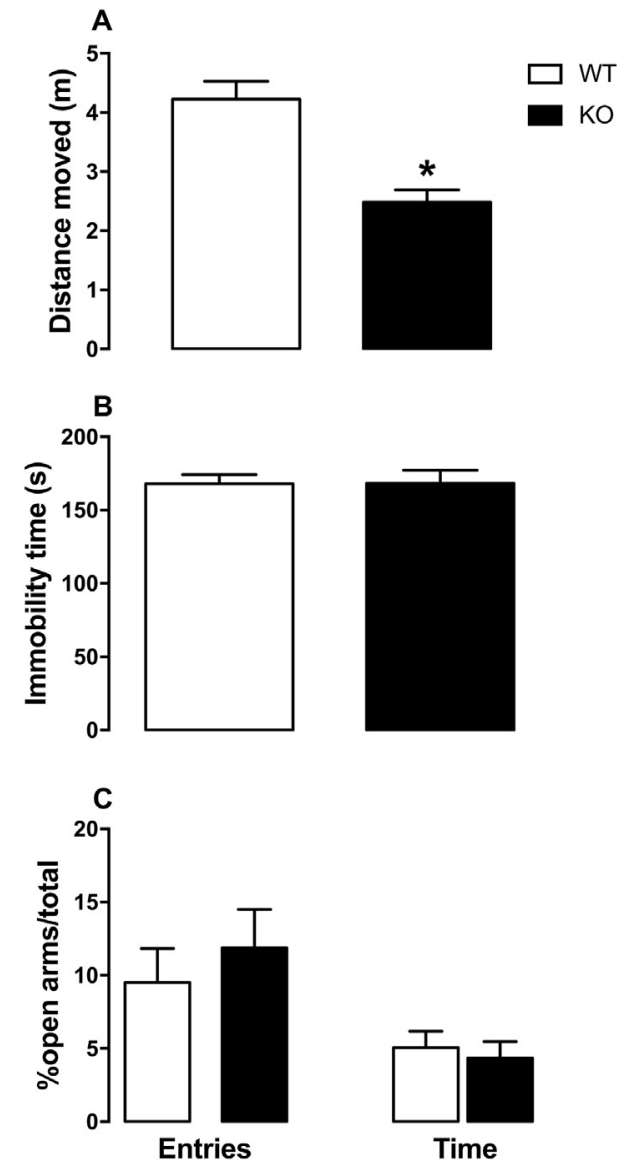

Fig. 4. Behavior of IL-18KO mice submitted to the open field (A) forced swimming test (B) or to the elevated plus maze (C). A) IL-18KO mice presented decreased distance moved. ${ }^{*} \mathrm{p}<0.05$, Student $t$-test; $\mathrm{n}=9$ /group. B and C) No significant effect in the immobility time nor in the exploration of the open arms were observed. Student $t$-test; $\mathrm{n}=13$ (WT) and 14 (KO) in the FST; 10 (WT) and 12 (KO) in the EPM. All data are expressed as mean \pm SEM.

described in psychiatric disorders, including schizophrenia. Considering the increased circulating levels of IL-18 and other cytokines in schizophrenic patients, it should be expected that IL-18 absence would rather facilitate PPI, instead of impairing it, as observed herein. In fact, it has been postulated that inflammatory processes would have a prominent role in the pathogenesis of schizophrenia (Monji et al., 2009). On the other hand, since IL-18 is structurally related to IL-1 $\beta$ and shares some biological functions with IL-12 (Dinarello, 1999; Trinchieri, 1995), it is possible that IL-18 deficiency would have induced an overcompensation of these two cytokines, which would then have been responsible for the schizophrenic-like phenotype of IL-18KO mice. In support of this hypothesis, we found increased levels of IL-1 $\beta$ and TNF$\alpha$ in brain regions of naïve IL-18KO mice. It was shown by others that these animals also present increased IL-12 and IFN- $\gamma$ levels in the hippocampus in response to neurodegenerative processes in the brain (Zhang et al., 2007). Accordingly, increased IFN- $\gamma / \mathrm{IL}-4$ ratio, IL-1 $\beta$ and IL- 6 are observed in schizophrenic patients, which are normalized by antipsychotic treatment (Kim et al., 2004; Miller et al., 2011). Therefore, an overcompensation of other cytokines under specific circumstances could have contributed to the development of neuroimmunological processes and subsequent structural and/or functional brain changes crucial for emotional regulation in IL-18KO mice.

Alternatively, IL-18 has also been suggested to mediate neuroprotective effects (Felderhoff-Mueser et al., 2005; Mori et al., 2001; Sugama et al., 2004). In patients with schizophrenia, lower levels of serum free IL-18 correlates with smaller hippocampal volume when compared with healthy individuals. IL-18 can also influence brain 

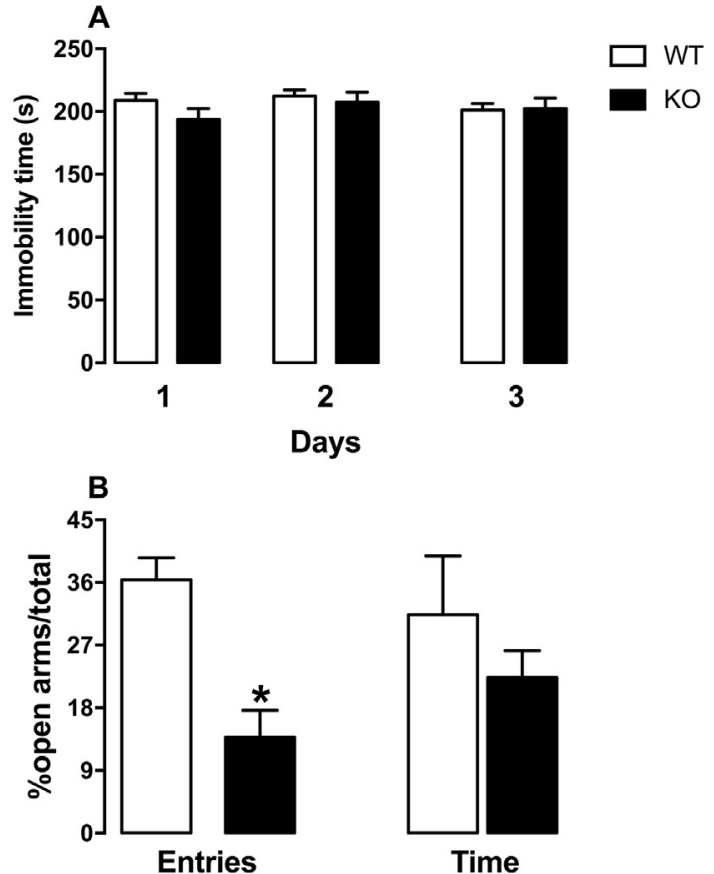

Time

Fig. 5. Behavior of IL-18KO mice submitted to repeated (5 days) forced swimming stress in the elevated plus maze. A) Immobility time was evaluated in the first, third and fifth day. No significant effect in the immobility time between IL-18KO and its wildtype (WT) counterparts was observed ( $p>0.05$, Student $t$-test; $n=10-12$ /group). B) In the elevated plus maze, repeated swimming stress decreased percentage of open arm entries and there was a tendency of decreased percentage of time exploring these arms in IL-18KO mice. Data are expressed as mean \pm SEM. *p $<0.05$ (Student $t$-test); $\mathrm{n}=10$ (WT) and 12 (KO).

maturation processes (Felderhoff-Mueser et al., 2005) and, therefore, its absence along brain development might have contributed to brain changes responsible for the PPI deficit observed in IL-18KO mice. Corroborating this hypothesis, the absence of other pro-inflammatory cytokines, such as IL-1 $\beta$, IL-6, and IL-2, during brain development was shown to promote significant cytoarchitectural changes in regions related to the neurobiology of schizophrenia, such as the striatum and the septo-hippocampal system (Parish et al., 2002; Petitto et al., 1999). However, considering that IL-18 can exacerbate Th1 (IFN- $\gamma$ related) or Th2 (IL-4 related) responses depending on the cytokine milieu (Nakanishi et al., 2001), the understanding of its role in schizophrenia is still incomplete.

PPI has been widely used as a translational model of sensorimotor gating ability. PPI disruption possibly reflects the difficulty of suppressing or filtering excessive information in schizophrenic patients (Braff et al., 2001, Swerdlow et al., 2008) and, therefore, PPI deficit has been considered to reflect a schizophrenic-like phenotype across species (Swerdlow et al., 2008). Accordingly, PPI is usually disrupted by drugs that increase dopaminergic neurotransmission (Geyer et al., 2001). In fact, dopamine appears to be very important in modulating PPI response in laboratory animals and humans, acting, at least in part, in the ventral striatum and frontal cortex (Bubser and Koch, 1994; Swerdlow et al., 1990).

Besides being altered by drugs, PPI can also be altered by developmental, lesion or genetic manipulation (for review (Deslauriers et al., 2013, Fone and Porkess, 2008, Jones et al., 2011). For instance, disruptions in brain development induced by genetic manipulation or inflammatory agents may lead to behavioral changes that correlate with the positive symptoms of schizophrenia, such as increased hyperlocomotion and dopamine release in the nucleus accumbens after amphetamine (Flagstad et al., 2004; Fortier et al., 2004; Lipska et al., 1993; Papaleo et al., 2012). In this scenario, the slight decrease of PPI response found in the IL-18KO mice and its differential response to amphetamine treatment could be related to developmental alterations of the dopaminergic system, probably due to the increased brain levels of inflammatory cytokines, as we observed in the hippocampus and medial prefrontal. Accordingly, maternal administration of poly I:C, a toll-like receptor 3 (TLR3) agonist which mimics the acute phase of viral infections (Meyer et al., 2006), induces alterations suggesting increased dopaminergic sensitivity, and later stress-induced PPI deficits (Deslauriers et al., 2013). These data suggest that increased inflammation during critical periods of brain development could alter dopaminergic system and disrupt PPI in later life. Overall, our results suggest that increased levels of some cytokines in IL-18KO mice brain could assemble the neurodevelopment hypothesis of schizophrenia (Brown, 2011; Fatemi and Folsom, 2009; Rapoport et al., 2012; Weinberger, 1987).

Dopaminergic dysfunction is one of the main neurochemical hypotheses for schizophrenia (Carlsson and Lindqvist, 1963; Laruelle, 2013; Seeman, 2013). It is suggested that psychotic patients release more dopamine after stimulation with amphetamine than normal individuals, suggesting increased midbrain dopaminergic activity (AbiDargham et al., 2009). Our data with IL-18KO mice showing increased hyperlocomotion after amphetamine treatment, therefore, suggest increased midbrain dopaminergic activity in those animals, resembling the positive symptoms of schizophrenia. At the dose used, amphetamine by itself did not disrupt PPI in WT mice, but normalized PPI response in IL-18KO mice, which could involve the hypodopaminergic prefrontal cortex function (Laruelle, 2013; Laruelle and Abi-Dargham, 1999; Seeman, 2013; Soares and Innis, 1999).

Social isolation, as used in the resident-intruder paradigm, is reported to induce behavioral alterations, such as aggressiveness (Chiavegatto and Nelson, 2003; Matsumoto et al., 2005), cognitive deficits and impaired PPI in rodents. Both aggression and antisocial behavior are observed in psychiatric disorders, including schizophrenia (Buckley et al., 2011, Buckley et al., 2004, Serper, 2011, Soyka, 2011). IL-18KO mice are more aggressive than their WT counterparts. In the resident-intruder test, the latency for the first attack is considered an index of reactivity or impulsivity, whereas the number and duration of attacks would reflect aggression per se (Nelson et al., 1995; Zhuang et al., 1999). We observed decreased latency and increased duration of attacks, suggesting that absence of IL-18 confers higher impulsivity and aggression. The dopaminergic system is activated when an offensive animal meets a defensive one (Ferrari et al., 2003). Moreover, whenever a resident mouse encounters an aggressive intruder mouse,

Table 1

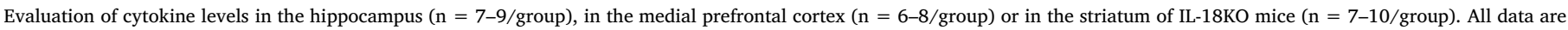
multiplied by $10^{-3}$. Data are given at $\mathrm{pg} / \mu \mathrm{g}$ of total protein and expressed as mean \pm SEM.

\begin{tabular}{|c|c|c|c|c|c|c|}
\hline & \multicolumn{2}{|l|}{ MPFC } & \multicolumn{2}{|l|}{ Striatum } & \multicolumn{2}{|l|}{ Hippocampus } \\
\hline & WT & IL-18 KO & WT & IL-18 KO & WT & IL-18 KO \\
\hline IL-1 $\beta$ & $5.8 \pm 2.1(\mathrm{n}=8)$ & $18.6 \pm 9.8(n=5)$ & $3.4 \pm 1.1(\mathrm{n}=6)$ & $18.6 \pm 8.0(n=7)$ & $4.3 \pm 1.2(\mathrm{n}=9)$ & $19.7 \pm 5.3^{*}(n=6)$ \\
\hline IL-33 & $52.8 \pm 14.4(\mathrm{n}=10)$ & $136.2 \pm 73.3(n=7)$ & $89.4 \pm 26.1(n=10)$ & $85.6 \pm 37.6(n=7)$ & $34.0 \pm 7.6(\mathrm{n}=9)$ & $24.3 \pm 4.1(\mathrm{n}=7)$ \\
\hline TNF- $\alpha$ & $82.5 \pm 6.2(\mathrm{n}=8)$ & $170 \pm 40.7^{*}(n=6)$ & $112.5 \pm 23.9(n=8)$ & $106.6 \pm 30.0(n=7)$ & $97.1 \pm 37.2(\mathrm{n}=9)$ & $78.7 \pm 19.4(\mathrm{n}=7)$ \\
\hline
\end{tabular}

${ }^{*} \mathrm{p}<0.05$, NS: non-significant. 
dopamine and other neurotransmitters increased in anticipation of the confrontation (Narvaes, 2014). Therefore, this data strengthens the proposition of high midbrain dopaminergic activity in IL-18KO mice. A previous work showed that although polymorphisms in IL-18 gene do not contribute to the susceptibility of schizophrenia in a Han Chinese population, a single-nucleotide polymorphism in that gene was associated with the presence of aggressive acts in the schizophrenic patients (Liu et al., 2011). In addition, although to our knowledge there is no work evaluating the direct involvement of IL-18 in aggressive behavior, cytokine immunotherapy increase aggressive traits in patients, which could be related to IL-1 $\beta$ (Pesce et al., 2011). This mechanism and the possible involvement of a dopaminergic imbalance need to be further investigated.

Regarding the participation of IL-18 in other stress-related psychiatric disorders, recent studies have investigated the behavioral phenotype of IL-18 null mice in different animal models. In line with our results, IL-18KO mice with 5-7 weeks old exhibited a significant deficit in the exploration of an open field (Yaguchi et al., 2010). Those mice also exhibited normal acquisition but less retention of a fear memory in the passive avoidance test (Yaguchi et al., 2010), suggesting an anxiolytic-like effect as recently demonstrated (Too et al., 2014). Older IL-18KO mice (12 weeks old), however, presented normal locomotor activity in the open field (Yamamoto et al., 2010). Although a reduction in the open field can be interpreted as increased anxiety levels, our results obtained with the EPM and previous one also using this model (Yaguchi et al., 2010) or another animal model of anxiety (Yamamoto et al., 2010) do not corroborate this idea. The different results among these studies could be due to different ages or animal background, with this latter factor being critical in the analysis of complex behaviors (Crawley, 2008; Crusio et al., 2009). While the genetic background of our IL-18KO mice is $\mathrm{Balb} / \mathrm{C}$, others have used C57BL/6.

Contrasting results presented herein, a previous report showed that IL-18KO mice presented decreased immobility time in the FST (Yamamoto et al., 2010). In that study, however, the mice adapted to the test on the next day, presenting immobility time similar to WT (Yamamoto et al., 2010). These studies, however, used IL-18KO mice with different genetic background. Another explanation for our negative results in the FST and EPM could be related to previous stress exposure. Stress is able to regulate IL-18 expression in a glucocorticoiddependent way (Conti et al., 1997; Conti et al., 2000; Sekiyama et al., 2005b; Sugama et al., 2000; Sugama et al., 2006) and IL-18 pattern of expression during stress has suggested that this cytokine modulates HPA axis activity in response to stress (Sekiyama et al., 2005a; Sugama and Conti, 2008).Therefore, in the present study the fact that after repeated swimming stress IL-18KO mice presented anxiogenic behavior support a role for IL-18 in controlling stress-induced HPA axis activation. Moreover, the increased stress-susceptibility in IL-18 null mice could be mediated by its impact on microglia activation (Mori et al., 2001, Sugama et al., 2004). These proposition, however, warrant further investigation.

In conclusion, corroborating the suggestion that pro-inflammatory cytokines are involved in the neurobiology of several psychiatric disorders (Monji et al., 2009, Stone et al., 2008, Sugama and Conti, 2008, Yaguchi et al., 2010), mice null for IL-18 presented increased levels of specific cytokines in limbic brain regions, impaired sensorimotor gating, increased sensitivity to amphetamine treatment, in addition to increased aggressive behavior and sensitivity to stress exposure. This knockout model, therefore, could provide new insights into how changes in brain immunological homeostasis induce behavioral changes related to psychiatric disorders such as schizophrenia.

\section{Acknowledgments}

The authors acknowledge Giuliana Bertozi, José C. de Aguiar, Eleni T. Gomes and Flavia F. Salatta for their excellent technical work, Felipe
V. Gomes for helpful discussions about schizophrenia hypothesis. This research was supported by grants from Brazil's foundations (FAPESP, CAPES, and CNPq). There is no conflict of interest.

\section{References}

Abel, E.L., Bilitzke, P.J., 1990. A possible alarm substance in the forced swimming test. Physiol. Behav, 48, 233-239.

Abi-Dargham, A., van de Giessen, E., Slifstein, M., Kegeles, L.S., Laruelle, M., 2009. Baseline and amphetamine-stimulated dopamine activity are related in drug-naive schizophrenic subjects. Biol. Psychiatry 65, 1091-1093.

Alboni, S., Cervia, D., Ross, B., Montanari, C., Gonzalez, A.S., Sanchez-Alavez, M., et al., 2009. Mapping of the full length and the truncated interleukin-18 receptor alpha in the mouse brain. J. Neuroimmunol. 214, 43-54.

Anisman, H., Merali, Z., 2002. Cytokines, stress, and depressive illness. Brain Behav. Immun. 16, 513-524.

Braff, D.L., Geyer, M.A., Swerdlow, N.R., 2001. Human studies of prepulse inhibition of startle: normal subjects, patient groups, and pharmacological studies. Psychopharmacology 156, 234-258.

Brown, A.S., 2011. Exposure to prenatal infection and risk of schizophrenia. Front. Psychiatry 2, 63.

Bubser, M., Koch, M., 1994. Prepulse inhibition of the acoustic startle response of rats is reduced by 6-hydroxydopamine lesions of the medial prefrontal cortex. Psychopharmacology 113, 487-492.

Buckley, P.F., Hrouda, D.R., Friedman, L., Noffsinger, S.G., Resnick, P.J., Camlin-Shingler, K., 2004. Insight and its relationship to violent behavior in patients with schizophrenia. Am. J. Psychiatry 161, 1712-1714.

Buckley, P., Citrome, L., Nichita, C., Vitacco, M., 2011. Psychopharmacology of aggression in schizophrenia. Schizophr. Bull. 37, 930-936.

Capuron, L., Pagnoni, G., Demetrashvili, M.F., Lawson, D.H., Fornwalt, F.B., Woolwine, B., et al., 2007. Basal ganglia hypermetabolism and symptoms of fatigue during interferon-alpha therapy. Neuropsychopharmacology 32, 2384-2392.

Carlsson, A., Lindqvist, M., 1963. Effect of chlorpromazine or haloperidol on formation of 3 methoxytyramine and normetanephrine in mouse brain. Acta Pharmacol. Toxicol. 20, 140-144.

Chiavegatto, S., Nelson, R.J., 2003. Interaction of nitric oxide and serotonin in aggressive behavior. Horm. Behav. 44, 233-241.

Conti, B., Jahng, J.W., Tinti, C., Son, J.H., Joh, T.H., 1997. Induction of interferon-gamma inducing factor in the adrenal cortex. J. Biol. Chem. 272, 2035-2037.

Conti, B., Sugama, S., Kim, Y., Tinti, C., Kim, H., Baker, H., et al., 2000. Modulation of IL18 production in the adrenal cortex following acute ACTH or chronic corticosterone treatment. Neuroimmunomodulation $8,1-7$.

Crawley, J.N., 2008. Behavioral phenotyping strategies for mutant mice. Neuron 57, 809-818.

Crusio, W.E., Goldowitz, D., Holmes, A., Wolfer, D., 2009. Standards for the publication of mouse mutant studies. Genes Brain Behav. 8, 1-4.

Culhane, A.C., Hall, M.D., Rothwell, N.J., Luheshi, G.N., 1998. Cloning of rat brain interleukin-18 cDNA. Mol. Psychiatry 3, 362-366.

Cunha, J.M., Cunha, F.Q., Poole, S., Ferreira, S.H., 2000. Cytokine-mediated inflammatory hyperalgesia limited by interleukin-1 receptor antagonist. Br. J. Pharmacol. 130, 1418-1424.

Curran, B., O'Connor, J.J., 2001. The pro-inflammatory cytokine interleukin-18 impairs long-term potentiation and NMDA receptor-mediated transmission in the rat hippocampus in vitro. Neuroscience 108, 83-90.

Deslauriers, J., Larouche, A., Sarret, P., Grignon, S., 2013. Combination of prenatal immune challenge and restraint stress affects prepulse inhibition and dopaminergic/ GABAergic markers. Prog. Neuro-Psychopharmacol. Biol. Psychiatry 45C, 156-164.

Dinarello, C.A., 1999. IL-18: a TH1-inducing, proinflammatory cytokine and new member of the IL-1 family. J. Allergy Clin. Immunol. 103, 11-24.

Drozdz, W., Borkowska, A., Wilkosc, M., Halota, W., Dybowska, D., Rybakowski, J.K., 2007. Chronic paranoid psychosis and dementia following interferon-alpha treatment of hepatitis C: a case report. Pharmacopsychiatry 40, 146-148.

Eisener-Dorman, A.F., Lawrence, D.A., Bolivar, V.J., 2010. Behavioral and genetic investigations of low exploratory behavior in Il18r1(-/-) mice: we can't always blame it on the targeted gene. Brain Behav. Immun. 24, 1116-1125.

Fatemi, S.H., Folsom, T.D., 2009. The neurodevelopmental hypothesis of schizophrenia, revisited. Schizophr. Bull. 35, 528-548.

Felderhoff-Mueser, U., Schmidt, O.I., Oberholzer, A., Buhrer, C., Stahel, P.F., 2005. IL-18: a key player in neuroinflammation and neurodegeneration? Trends Neurosci. 28, 487-493.

Ferrari, P.F., van Erp, A.M., Tornatzky, W., Miczek, K.A., 2003. Accumbal dopamine and serotonin in anticipation of the next aggressive episode in rats. Eur. J. Neurosci. 17, 371-378.

Flagstad, P., Mork, A., Glenthoj, B.Y., van Beek, J., Michael-Titus, A.T., Didriksen, M., 2004. Disruption of neurogenesis on gestational day 17 in the rat causes behavioral changes relevant to positive and negative schizophrenia symptoms and alters amphetamine-induced dopamine release in nucleus accumbens. Neuropsychopharmacology 29, 2052-2064.

Fone, K.C., Porkess, M.V., 2008. Behavioural and neurochemical effects of post-weaning social isolation in rodents-relevance to developmental neuropsychiatric disorders. Neurosci. Biobehav. Rev. 32, 1087-1102.

Fortier, M.E., Joober, R., Luheshi, G.N., Boksa, P., 2004. Maternal exposure to bacterial endotoxin during pregnancy enhances amphetamine-induced locomotion and startle responses in adult rat offspring. J. Psychiatr. Res. 38, 335-345. 
Geyer, M.A., Krebs-Thomson, K., Braff, D.L., Swerdlow, N.R., 2001. Pharmacological studies of prepulse inhibition models of sensorimotor gating deficits in schizophrenia: a decade in review. Psychopharmacology 156, 117-154.

Glaser, R., Kiecolt-Glaser, J.K., 2005. Stress-induced immune dysfunction: implications for health. Nat. Rev. Immunol. 5, 243-251.

Goshen, I., Yirmiya, R., 2009. Interleukin-1 (IL-1): a central regulator of stress responses. Front. Neuroendocrinol. 30, 30-45.

Goshen, I., Kreisel, T., Ounallah-Saad, H., Renbaum, P., Zalzstein, Y., Ben-Hur, T., et al., 2007. A dual role for interleukin-1 in hippocampal-dependent memory processes. Psychoneuroendocrinology 32, 1106-1115.

Hoffman, H.S., Ison, J.R., 1980. Reflex modification in the domain of startle: I. Some empirical findings and their implications for how the nervous system processes sensory input. Psychol. Rev. 87, 175-189.

Issy, A.C., Salum, C., Del Bel, E.A., 2009. Nitric oxide modulation of methylphenidateinduced disruption of prepulse inhibition in Swiss mice. Behav. Brain Res. 205, 475-481.

Jones, C.A., Watson, D.J., Fone, K.C., 2011. Animal models of schizophrenia. Br. J. Pharmacol. 164, 1162-1194.

Kanno, T., Nagata, T., Yamamoto, S., Okamura, H., Nishizaki, T., 2004. Interleukin-18 stimulates synaptically released glutamate and enhances postsynaptic AMPA receptor responses in the CA1 region of mouse hippocampal slices. Brain Res. 1012, 190-193.

Kim, Y.K., Myint, A.M., Lee, B.H., Han, C.S., Lee, H.J., Kim, D.J., et al., 2004. Th1, Th2 and Th3 cytokine alteration in schizophrenia. Prog. Neuro-Psychopharmacol. Biol. Psychiatry 28, 1129-1134.

Kumar, A., Garg, R., Gaur, V., Kumar, P., 2010. Venlafaxine involves nitric oxide modulatory mechanism in experimental model of chronic behavior despair in mice. Brain Res. 1311, 73-80.

Kusnecov, A.W., Rabin, B.S., 1994. Stressor-induced alterations of immune function: mechanisms and issues. Int. Arch. Allergy Immunol. 105, 107-121.

Kwon, M.S., Seo, Y.J., Lee, J.K., Lee, H.K., Jung, J.S., Jang, J.E., et al., 2008. The repeated immobilization stress increases IL-1beta immunoreactivities in only neuron, but not astrocyte or microglia in hippocampal CA1 region, striatum and paraventricular nucleus. Neurosci. Lett. 430, 258-263.

Laruelle, M., 2013. The second revision of the dopamine theory of schizophrenia: implications for treatment and drug development. Biol. Psychiatry 74, 80-81.

Laruelle, M., Abi-Dargham, A., 1999. Dopamine as the wind of the psychotic fire: new evidence from brain imaging studies. J. Psychopharmacol. 13, 358-371.

Leite, J.V., Guimaraes, F.S., Moreira, F.A., 2008. Aripiprazole, an atypical antipsychotic, prevents the motor hyperactivity induced by psychotomimetics and psychostimulants in mice. Eur. J. Pharmacol. 578, 222-227.

Levine, J., Barak, Y., Chengappa, K.N., Rapoport, A., Rebey, M., Barak, V., 1999. Cerebrospinal cytokine levels in patients with acute depression. Neuropsychobiology 40, 171-176.

Licinio, J., Wong, M.L., 1999. The role of inflammatory mediators in the biology of major depression: central nervous system cytokines modulate the biological substrate of depressive symptoms, regulate stress-responsive systems, and contribute to neurotoxicity and neuroprotection. Mol. Psychiatry 4, 317-327.

Lipska, B.K., Jaskiw, G.E., Weinberger, D.R., 1993. Postpubertal emergence of hyperresponsiveness to stress and to amphetamine after neonatal excitotoxic hippocampal damage: a potential animal model of schizophrenia. Neuropsychopharmacology 9, $67-75$.

Lisboa, S.F., Oliveira, P.E., Costa, L.C., Venancio, E.J., Moreira, E.G., 2007. Behavioral evaluation of male and female mice pups exposed to fluoxetine during pregnancy and lactation. Pharmacology 80, 49-56.

Liu, J., Liu, J., Zhou, Y., Li, S., Li, Y., Song, X., et al., 2011. Association between promoter variants of interleukin-18 and schizophrenia in a Han Chinese population. DNA Cell Biol. 30, 913-917.

Madrigal, J.L., Hurtado, O., Moro, M.A., Lizasoain, I., Lorenzo, P., Castrillo, A., et al., 2002. The increase in TNF-alpha levels is implicated in NF-kappaB activation and inducible nitric oxide synthase expression in brain cortex after immobilization stress. Neuropsychopharmacology 26, 155-163.

Maes, M., 1995. Evidence for an immune response in major depression: a review and hypothesis. Prog. Neuro-Psychopharmacol. Biol. Psychiatry 19, 11-38.

Maes, M., 1999. Major depression and activation of the inflammatory response system. Adv. Exp. Med. Biol. 461, 25-46.

Matsumoto, K., Pinna, G., Puia, G., Guidotti, A., Costa, E., 2005. Social isolation stressinduced aggression in mice: a model to study the pharmacology of neurosteroidogenesis. Stress 8, 85-93.

Meyer, U., Feldon, J., Schedlowski, M., Yee, B.K., 2006. Immunological stress at the maternal-foetal interface: a link between neurodevelopment and adult psychopathology. Brain Behav. Immun. 20, 378-388.

Miller, B.J., Buckley, P., Seabolt, W., Mellor, A., Kirkpatrick, B., 2011. Meta-analysis of cytokine alterations in schizophrenia: clinical status and antipsychotic effects. Biol. Psychiatry 70, 663-671.

Monji, A., Kato, T., Kanba, S., 2009. Cytokines and schizophrenia: microglia hypothesis of schizophrenia. Psychiatry Clin. Neurosci. 63, 257-265.

Mori, I., Hossain, M.J., Takeda, K., Okamura, H., Imai, Y., Kohsaka, S., et al., 2001. Impaired microglial activation in the brain of IL-18-gene-disrupted mice after neurovirulent influenza A virus infection. Virology 287, 163-170.

Nakanishi, K., Yoshimoto, T., Tsutsui, H., Okamura, H., 2001. Interleukin-18 regulates both Th1 and Th2 responses. Annu. Rev. Immunol. 19, 423-474.

Narvaes, RdARM, 2014. Aggressive behavior and three neurotransmitters: dopamine, GABA, and serotonin - a review of the last 10 years. Psychol. Neurosci. 7, 601-607.

Nelson, R.J., Demas, G.E., Huang, P.L., Fishman, M.C., Dawson, V.L., Dawson, T.M., et al., 1995. Behavioural abnormalities in male mice lacking neuronal nitric oxide synthase. Nature 378, 383-386.
O'Connor, K.A., Johnson, J.D., Hansen, M.K., Wieseler Frank, J.L., Maksimova, E., Watkins, L.R., et al., 2003. Peripheral and central proinflammatory cytokine response to a severe acute stressor. Brain Res. 991, 123-132.

Okamura, H., Tsutsi, H., Komatsu, T., Yutsudo, M., Hakura, A., Tanimoto, T., et al., 1995. Cloning of a new cytokine that induces IFN-gamma production by T cells. Nature 378, 88-91.

Orhan, F., Fatouros-Bergman, H., Schwieler, L., Cervenka, S., Flyckt, L., Sellgren, C.M., et al., 2017. First-episode psychosis patients display increased plasma IL-18 that correlates with cognitive dysfunction. Schizophr. Res.

Papaleo, F., Yang, F., Garcia, S., Chen, J., Lu, B., Crawley, J.N., et al., 2012. Dysbindin-1 modulates prefrontal cortical activity and schizophrenia-like behaviors via dopamine/D2 pathways. Mol. Psychiatry 17, 85-98.

Papanicolaou, D.A., Wilder, R.L., Manolagas, S.C., Chrousos, G.P., 1998. The pathophysiologic roles of interleukin-6 in human disease. Ann. Intern. Med. 128, 127-137.

Parish, C.L., Finkelstein, D.I., Tripanichkul, W., Satoskar, A.R., Drago, J., Horne, M.K., 2002. The role of interleukin-1, interleukin-6, and glia in inducing growth of neuronal terminal arbors in mice. J. Neurosci. 22, 8034-8041.

Penninx, B.W., Kritchevsky, S.B., Yaffe, K., Newman, A.B., Simonsick, E.M., Rubin, S., et al., 2003. Inflammatory markers and depressed mood in older persons: results from the Health, Aging and Body Composition study. Biol. Psychiatry 54, 566-572.

Pesce, M., Speranza, L., Franceschelli, S., Ialenti, V., Patruno, A., Febo, M.A., et al., 2011. Biological role of interleukin-1beta in defensive-aggressive behaviour. J. Biol. Regul. Homeost. Agents 25, 323-329.

Petitto, J.M., McNamara, R.K., Gendreau, P.L., Huang, Z., Jackson, A.J., 1999. Impaired learning and memory and altered hippocampal neurodevelopment resulting from interleukin-2 gene deletion. J. Neurosci. Res. 56, 441-446.

Pickering, M., Cumiskey, D., O'Connor, J.J., 2005. Actions of TNF-alpha on glutamatergic synaptic transmission in the central nervous system. Exp. Physiol. 90, 663-670.

Porsolt, R.D., Le Pichon, M., Jalfre, M., 1977. Depression: a new animal model sensitive to antidepressant treatments. Nature 266, 730-732.

Rapoport, J.L., Giedd, J.N., Gogtay, N., 2012. Neurodevelopmental model of schizophrenia: update 2012. Mol. Psychiatry 17, 1228-1238.

Schiepers, O.J., Wichers, M.C., Maes, M., 2005. Cytokines and major depression. Prog. Neuro-Psychopharmacol. Biol. Psychiatry 29, 201-217.

Seeman, P., 2013. Schizophrenia and dopamine receptors. Eur. Neuropsychopharmacol. 23, 999-1009.

Segerstrom, S.C., Miller, G.E., 2004. Psychological stress and the human immune system: a meta-analytic study of 30 years of inquiry. Psychol. Bull. 130, 601-630.

Sekiyama, A., Ueda, H., Kashiwamura, S., Nishida, K., Kawai, K., Teshima-kondo, S., et al., 2005a. IL-18; a cytokine translates a stress into medical science. J. Med. Investig. 52 (Suppl), 236-239.

Sekiyama, A., Ueda, H., Kashiwamura, S., Sekiyama, R., Takeda, M., Rokutan, K., et al., 2005b. A stress-induced, superoxide-mediated caspase-1 activation pathway causes plasma IL-18 upregulation. Immunity 22, 669-677.

Serper, M.R., 2011. Aggression in schizophrenia. Schizophr. Bull. 37, 897-898.

Soares, J.C., Innis, R.B., 1999. Neurochemical brain imaging investigations of schizophrenia. Biol. Psychiatry 46, 600-615.

Soyka, M., 2011. Neurobiology of aggression and violence in schizophrenia. Schizophr. Bull. 37, 913-920.

Stellwagen, D., Malenka, R.C., 2006. Synaptic scaling mediated by glial TNF-alpha. Nature 440, 1054-1059.

Stone, E.A., Lin, Y., Quartermain, D., 2008. A final common pathway for depression? Progress toward a general conceptual framework. Neurosci. Biobehav. Rev. 32, 508-524.

Sugama, S., Conti, B., 2008. Interleukin-18 and stress. Brain Res. Rev. 58, 85-95.

Sugama, S., Kim, Y., Baker, H., Tinti, C., Kim, H., Joh, T.H., et al., 2000. Tissue-specific expression of rat IL-18 gene and response to adrenocorticotropic hormone treatment. J. Immunol. 165, 6287-6292.

Sugama, S., Wirz, S.A., Barr, A.M., Conti, B., Bartfai, T., Shibasaki, T., 2004. Interleukin18 null mice show diminished microglial activation and reduced dopaminergic neuron loss following acute 1-methyl-4-phenyl-1,2,3,6-tetrahydropyridine treatment. Neuroscience 128, 451-458.

Sugama, S., Wang, N., Shimokawa, N., Koibuchi, N., Fujita, M., Hashimoto, M., et al., 2006. The adrenal gland is a source of stress-induced circulating IL-18. J. Neuroimmunol. 172, 59-65.

Sugama, S., Fujita, M., Hashimoto, M., Conti, B., 2007. Stress induced morphological microglial activation in the rodent brain: involvement of interleukin-18. Neuroscience 146, 1388-1399.

Swerdlow, N.R., Braff, D.L., Masten, V.L., Geyer, M.A., 1990. Schizophrenic-like sensorimotor gating abnormalities in rats following dopamine infusion into the nucleus accumbens. Psychopharmacology 101, 414-420.

Swerdlow, N.R., Weber, M., Qu, Y., Light, G.A., Braff, D.L., 2008. Realistic expectations of prepulse inhibition in translational models for schizophrenia research. Psychopharmacology 199, 331-388.

Tanaka, K.F., Shintani, F., Fujii, Y., Yagi, G., Asai, M., 2000. Serum interleukin-18 levels are elevated in schizophrenia. Psychiatry Res. 96, 75-80.

Tonelli, L.H., Postolache, T.T., 2005. Tumor necrosis factor alpha, interleukin-1 beta, interleukin- 6 and major histocompatibility complex molecules in the normal brain and after peripheral immune challenge. Neurol. Res. 27, 679-684.

Too, L.K., Mitchell, A.J., Yau, B., Ball, H.J., McGregor, I.S., Hunt, N.H., 2014. Interleukin18 deficiency and its long-term behavioural and cognitive impacts in a murine model of pneumococcal meningitis. Behav. Brain Res. 263, 176-189.

Trinchieri, G., 1995. Interleukin-12: a proinflammatory cytokine with immunoregulatory functions that bridge innate resistance and antigen-specific adaptive immunity. Annu. Rev. Immunol. 13, 251-276.

Tuglu, C., Kara, S.H., Caliyurt, O., Vardar, E., Abay, E., 2003. Increased serum tumor 
necrosis factor-alpha levels and treatment response in major depressive disorder. Psychopharmacology 170, 429-433.

Wei, X.Q., Leung, B.P., Niedbala, W., Piedrafita, D., Feng, G.J., Sweet, M., et al., 1999. Altered immune responses and susceptibility to Leishmania major and Staphylococcus aureus infection in IL-18-deficient mice. J. Immunol. 163, 2821-2828.

Weinberger, D.R., 1987. Implications of normal brain development for the pathogenesis of schizophrenia. Arch. Gen. Psychiatry 44, 660-669.

Wheeler, R.D., Culhane, A.C., Hall, M.D., Pickering-Brown, S., Rothwell, N.J., Luheshi, G.N., 2000. Detection of the interleukin 18 family in rat brain by RT-PCR. Brain Res. Mol. Brain Res. 77, 290-293.

Wu, J.Q., Chen, D.C., Tan, Y.L., Tan, S.P., Xiu, M.H., Wang, Z.R., et al., 2016. Altered interleukin-18 levels are associated with cognitive impairment in chronic schizophrenia. J. Psychiatr. Res. 76, 9-15.

Xiu, M.H., Chen, D.C., Wang, D., Zhang, K., Dong, A., Tang, W., et al., 2012. Elevated interleukin-18 serum levels in chronic schizophrenia: association with psychopathology. J. Psychiatr. Res. 46 (8), 1093.

Yaguchi, T., Nagata, T., Yang, D., Nishizaki, T., 2010. Interleukin-18 regulates motor activity, anxiety and spatial learning without affecting synaptic plasticity. Behav.
Brain Res. 206, 47-51.

Yamamoto, Y., Tanahashi, T., Katsuura, S., Kurokawa, K., Nishida, K., Kuwano, Y., et al., 2010. Interleukin-18 deficiency reduces neuropeptide gene expressions in the mouse amygdala related with behavioral change. J. Neuroimmunol. 229, 129-139.

Yirmiya, R., 2000. Depression in medical illness: the role of the immune system. West $\mathrm{J}$ Med. 173, 333-336.

Zanelati, T., Biojone, C., Moreira, F., Guimaraes, F., Joca, S., 2009. Antidepressant-like effects of cannabidiol in mice: possible involvement of 5-HT receptors. Br. J. Pharmacol.

Zhang, X.M., Duan, R.S., Chen, Z., Quezada, H.C., Mix, E., Winblad, B., et al., 2007. IL-18 deficiency aggravates kainic acid-induced hippocampal neurodegeneration in C57BL/6 mice due to an overcompensation by IL-12. Exp. Neurol. 205, 64-73.

Zhang, X.Y., Tang, W., Xiu, M.H., Chen, da C., Yang, F.D., Tan, Y.L., et al., 2013. Interleukin 18 and cognitive impairment in first episode and drug naive schizophrenia versus healthy controls. Brain Behav. Immun. 32, 105-111.

Zhuang, X., Gross, C., Santarelli, L., Compan, V., Trillat, A.C., Hen, R., 1999. Altered emotional states in knockout mice lacking 5-HT1A or 5-HT1B receptors. Neuropsychopharmacology 21, 52S-60S. 